\title{
Bases Teóricas de Bem-Estar Subjetivo, Bem-Estar Psicológico e Bem-Estar no Trabalho
}

\author{
Mirlene Maria Matias Siqueira ${ }^{1}$ \\ Valquiria Aparecida Rossi Padovam \\ Universidade Metodista de São Paulo
}

\begin{abstract}
RESUMO - A concepção de saúde inclui bem-estar como um conceito chave. Em decorrência, encontram-se na literatura diferentes proposições teóricas para bem-estar. Este artigo tem como objetivo apresentar duas visões tradicionais e uma concepção nova sobre bem-estar. Inicialmente, são revisadas as bases teóricas que sustentam o bem-estar subjetivo. As concepções sobre bem-estar psicológico, ancoradas nas teorias que desenharam os primórdios da psicologia positiva, são apresentadas na segunda seção. Na seqüência, o conceito de bem-estar no trabalho é formulado apontando-se seus componentes assentados em vínculos positivos com o trabalho e com a organização. Na seção que encerra o artigo, sugere-se uma articulação, com base nas proposições da psicologia positiva, no intuito de ampliar a compreensão de fatores que contribuem para promover uma existência mais saudável.
\end{abstract}

Palavras-chave: bem-estar subjetivo; bem-estar psicológico; bem-estar no trabalho.

\section{Theoretical Basis of Subjective Well-Being, Psychological Well-Being and Well- Being at Work}

\begin{abstract}
The definition of health includes well-being as a prime concept. Following it, there are different theoretical propositions to well-being in literature. This article presents two traditional views and a new conception about well-being. First of all, theoretical basis that sustains subjective well-being is revised. Conceptions about psychological well-being that draw the beginning about positive psychology are showed in the second section. Next, the concept of well-being at work is formulated ponting out your component, which were established in positive links between job and organization. In the end, it is suggested an articulation, based on positive psychology proposition, in order to broaden the understanding of factors that contribute to promote a healthy existence.
\end{abstract}

Key words: subjective well-being; psychological well-being; well-being at work.

Um componente largamente reconhecido como principal integrante de uma vida saudável é a felicidade (Diener, Scollon \& Lucas, 2003). Embora o estilo de vida moderno não estimule as pessoas a avaliar seus momentos de felicidade ou de completa realização pessoal, elas são diariamente incitadas a planejar o seu dia-a-dia para vencer os desafios da vida moderna como, por exemplo, conseguir e manter um emprego, proteger suas vidas da violência urbana, equilibrar as finanças, esquivar-se de hábitos ou estilos de vida que comprometem a sua saúde e, ao mesmo tempo, praticar ações que promovem a sua integridade física, emocional e social. Pesquisadores espalhados por diversos países estão empenhados em descobrir o quanto as pessoas se consideram felizes ou em que medida são capazes de realizar plenamente suas potencialidades. Esses estudiosos, embora utilizem duas perspectivas distintas, investigam um tema complexo denominado bem-estar.

A atenção dispensada ao tema não é recente. Desde a Grécia antiga, filósofos como Aristóteles já tentavam decifrar o enigma da existência feliz. Enquanto filósofos ainda debatem a essência do estado de felicidade, pesquisadores empenharam-se, nas últimas três décadas, para construir

1 Endereço: Rua , Myriam Dora Rossi, nº 100, aptº 84, Chácara Inglesa, São Bernardo do Campo, SP Brasil 09726 100.E-mail: mirlenesiqueira@uol. com.br conhecimento e trazer evidências científicas sobre bem-estar. Desses desafios estão participando diversos estudiosos que conseguiram, após décadas de investigações, instalar o conceito de bem-estar no campo científico da psicologia e transformá-lo em um dos temas mais enfaticamente discutidos e aplicados para compreender os fatores psicológicos que integram uma vida saudável.

As concepções científicas mais proeminentes da atualidade sobre bem-estar no campo psicológico podem, segundo Ryan e Deci (2001), ser organizadas em duas perspectivas: uma que aborda o estado subjetivo de felicidade (bem-estar hedônico), e se denomina bem-estar subjetivo, e outra que investiga o potencial humano (bem-estar eudemônico) e trata de bem-estar psicológico. Na visão desses autores, essas duas tradições de estudo refletem visões filosóficas distintas sobre felicidade: enquanto a primeira (hedonismo) adota uma visão de bem-estar como prazer ou felicidade, a segunda (eudemonismo) apoia-se na noção de que bemestar consiste no pleno funcionamento das potencialidades de uma pessoa, ou seja, em sua capacidade de pensar, usar o raciocínio e o bom senso.

Este artigo tem por objetivos apresentar as duas abordagens tradicionais sobre bem-estar - subjetivo e psicológico - e introduzir uma concepção teórica mais estruturada sobre bem-estar no ambiente de trabalho. 


\section{Bem-Estar Subjetivo}

Bem-estar subjetivo (BES) constitui um campo de estudos que procura compreender as avaliações que as pessoas fazem de suas vidas (Diener, Suh \& Oishi, 1997). Esse campo teve um crescimento acelerado na última década, revelando como seus principais tópicos de pesquisa satisfação e felicidade (Diener \& cols., 2003). Tais avaliações devem ser cognitivas (satisfações globais com a vida e com outros domínios específicos como com o casamento e o trabalho) e devem incluir também uma análise pessoal sobre a freqüiência com que se experimentam emoções positivas e negativas. Para que seja relatado um nível de BES adequado, é necessário que o indivíduo reconheça manter em nível elevado sua satisfação com a vida, alta frequiência de experiências emocionais positivas e baixas frequiências de experiências emocionais negativas. Ainda segundo Diener e cols. (1997), nesse campo de conhecimento não se procura estudar estados psicológicos negativos ou patológicos, tais como depressão, ansiedade e estresse, mas diferenciar os níveis de bem-estar que as pessoas conseguem alcançar em suas vidas. Essas concepções reafirmam que BES compreende um tema aderente aos princípios defendidos pelos atuais propagadores (Seligman \& Csikszentmihalyi, 2000) da psicologia positiva.

O conceito de BES apareceu ao final dos anos 1950, quando se buscavam indicadores de qualidade de vida para monitorar mudanças sociais e implantação de políticas sociais (Land, 1975). Como marcos da literatura sobre o tema durante a década de 1960, podem ser apontados os livros de Andrews e Withey (1976) e Campbell, Converge e Rodgers (1976), por preconizarem que, embora as pessoas vivam em ambientes objetivamente definidos, é ao mundo subjetivamente definido que elas respondem. Nessa perspectiva, BES tornou-se um importante indicador de qualidade de vida. Outras influentes obras sobre o assunto foram três trabalhos (Bradburn, 1969; Cantril, 1967; Gurin, Veroff \& Feld 1960) que enfatizaram satisfação com a vida e felicidade como elementos integrantes do conceito de qualidade de vida. Os dois componentes que integram a visão contemporânea de BES - satisfação com a vida e afetos positivos e negativos - tiveram sua gênese nos trabalhos seminais de Campbell e cols. (1976) e de Bradburn (1969).

A primeira revisão sobre BES foi realizada por Wilson em 1967, num estudo intitulado "Correlatos de Felicidade Declarada". Embora naquela época os dados sobre o assunto fossem limitados, Wilson (1967, p. 294) pôde concluir que entre pessoas felizes incluíam-se as que eram "[...] jovens, com boa educação, bons salários, extrovertidas, otimistas, despreocupadas, com religiosidade, casadas, elevada autoestima, moral no trabalho, aspirações modestas, de ambos os gêneros e que detinham diversificados níveis de inteligência". Atualmente, o interesse de pesquisadores não se limita mais à descrição dos atributos de pessoas felizes, nem tampouco a identificar correlações entre características demográficas e níveis de BES. O esforço atual dos pesquisadores está orientado pela busca de compreensão do processo que sustenta a felicidade (Diener, Suh, Lucas \& Smith, 1999).

Atualmente, BES é concebido por Diener e Lucas (2000) como um conceito que requer auto-avaliação, ou seja, ele só pode ser observado e relatado pelo próprio indivíduo e não por indicadores externos escolhidos e definidos por terceiros. Consoante essa visão, não é considerado adequado avaliar BES por meio de indicadores externos ao indivíduo, mesmo que tenham como base fatores estatisticamente construídos, tais como controle de doenças, queda da mortalidade infantil, redução dos índices de criminalidade e violência, queda de taxas de desemprego ou de analfabetismo, bem como outros indicadores aplicados para descrever avanços em políticas sociais e que projetam a qualidade de vida de extratos sociais, comunidades ou de nações.

Para acessar o BES, é necessário considerar que cada pessoa avalia sua própria vida aplicando concepções subjetivas e, nesse processo, apoia-se em suas próprias expectativas, valores, emoções e experiências prévias. Essas concepções subjetivas, segundo Diener e Lucas (2000), estão organizadas em pensamentos e sentimentos sobre a existência individual.

Parece existir, portanto, uma representação mental (cognitiva) sobre a vida pessoal, organizada e armazenada subjetivamente, sobre a qual pesquisadores de BES procuram obter informações quando solicitam às pessoas relatos sobre ela. Deve-se ressaltar que a avaliação feita pelo próprio indivíduo sobre seu BES inclui, entre outros aspectos, componentes positivos que não envolvem, necessariamente, elementos de prosperidade econômica (Diener \& cols., 1999).

No Brasil, já existem estudos focalizando o bem-estar subjetivo. Os autores têm se dedicado a construir e validar medidas de bem-estar subjetivo (Albuquerque \& Troccoli, 2004; Siqueira, Martins e Moura, 1999), a investigar seus antecedentes (Freire, 2001) e suas relações com sentimentos de solidão e interações sociais (Capitanini, 2000), bem como a analisar a influência de bem-estar subjetivo sobre qualidade de vida (Prebianchi, 2003).

Existe um entendimento por parte de diversos estudiosos (Diener \& cols., 1997; Diener \& cols., 1999; Diener \& Lucas, 2000) de que BES se constitui em um amplo fenômeno e deve ser considerado como uma área de interesse científico que engloba dois conceitos específicos: julgamentos globais de satisfação com a vida, ou com domínios específicos dela, e experiências emocionais positivas e negativas (Diener \& cols., 1999). Nesse sentido, o conceito de BES articula duas perspectivas em psicologia: uma que se assenta nas teorias sobre estados emocionais, emoções, afetos e sentimentos (afetos positivos e afetos negativos) e outra que se sustenta nos domínios da cognição e se operacionaliza por avaliações de satisfação (com a vida em geral, com aspectos específicos da vida como o trabalho).

\section{A dimensão emocional de BES: afetos positivos e negativos}

A composição emocional do conceito BES inclui um balanço entre duas dimensões emocionais: emoções positivas e emoções negativas. Para que o balanço represente uma dimensão de BES, é necessário resultar em uma relação positiva entre as emoções vividas, qual seja, a vivência de mais emoções positivas do que negativas no decorrer da vida. Esta dimensão de BES guarda forte relação com a visão hedônica de felicidade, na medida em que dá ênfase aos aspectos afetivos da vida (Keyes, Shmotkin \& Ryff, 2002).

Quando se estudam os afetos positivos e negativos, não se trata de identificar a presença contínua de sensações positivas em toda a vida, mas, sim, detectar se, em sua grande maioria, 
as experiências vividas foram entremeadas muito mais por emoções prazerosas do que por sofrimentos. Segundo alguns pesquisadores (Andrews \& Robinson, 1991; Diener \& Diener, 1996; Thomas \& Diener, 1990), as pessoas costumam relatar maior constância de emoções positivas do que negativas em suas vidas. Por outro lado, estudos têm revelado que pessoas que tendem a viver intensas emoções positivas são as que também tendem a relatar fortes experiências emocionais negativas (Diener \& Lucas, 2000). Thomas e Diener (1990) relataram que a memorização de experiências emocionais não é precisa. Tais resultados de pesquisa levaram Diener e Lucas (2000) a sugerir aos pesquisadores cautela para não considerarem os relatos sobre experiências emocionais como fiéis às situações realmente vividas.

Por que as experiências emocionais são importantes para as avaliações que uma pessoa faz do seu BES? Segundo Diener e Lucas (2000), as análises sobre bem-estar podem estar muito mais relacionadas à frequiência com que se experimentam emoções positivas do que à intensidade dessas emoções. Explicam os dois autores que, ao se levar em conta na avaliação do BES mais a freqüência do que a intensidade de emoções positivas, as pessoas estão considerando, provavelmente, serem as emoções positivas intensas muito raras e também porque estas são, muitas vezes, acompanhadas por alguns custos para o indivíduo que as experimenta. Existem evidências em estudos sobre afetos (Diener \& Diener, 1996) e satisfação com a vida (Andrews, 1991), revelando que as pessoas tendem a relatar mais vivências de afetos positivos do que negativos e a revelar satisfações com a vida em níveis acima do nível médio das medidas aplicadas, independentemente da idade, do nível sócio-econômico ou etnia dos grupos pesquisados.

O debate sobre os componentes emocionais do BES teve suas primeiras formulações no trabalho seminal de Bradburn (1969). Este pesquisador defendia a idéia de que os afetos positivos e negativos não eram duas polaridades de um mesmo contínuo, mas formavam dois contínuos distintos de afetividade, capazes de apresentar correlações particulares com conjuntos específicos de traços de personalidade. Bradburn propôs uma estrutura bidimensional para os afetos: afetos positivos e afetos negativos.

Segundo Diener e Emmons (1985), os trabalhos de Bradburn (1969) e Bradburn e Caplovitz (1965) não só introduziram o debate acerca da definição de felicidade nos domínios da psicologia como também apontaram uma forma de mensurá-la por duas dimensões relativamente independentes uma da outra. $\mathrm{Na}$ visão de Bradburn e Caplovitz (1965), felicidade ou bem-estar subjetivo seria um construto composto por dois conjuntos de sentimentos separados: afetos positivos (AP) e afetos negativos (AN). Para avaliá-los, esses estudiosos usavam 10 itens agrupados em duas escalas, sendo cinco para avaliar AP (Positive Affect Scale, ou PAS) e outros cinco para aferir AN (Negative Affect Scale, ou NAS). Numa série de estudos desenvolvidos por esses pesquisadores, foram observadas correlações fracas entre os itens das duas escalas, altas correlações entre os itens de cada escala e correlações diferenciadas de cada escala com diversas outras variáveis. Esses resultados levaram Bradburn e colaboradores a reafirmar a relativa independência entre $\mathrm{AP}$ e $\mathrm{AN}$ e a apontá-los como duas dimensões na estrutura dos afetos.

Ainda nos anos 1960, Ostrom (1969) defendia a noção de BES ser uma atitude, apoiando-se na noção largamente difundida naquela época de que as atitudes eram compostas por elementos cognitivos e afetivos. Consoante esse entendimento, BES como uma atitude teria componentes cognitivos ou intelectuais, bem como envolveria aspectos emocionais. As discussões sobre quais componentes afetivos integrariam BES provocaram a indicação de um variado leque de conceitos psicológicos, sendo especialmente apontados para sua composição traços como ansiedade e depressão para representar afetos negativos. Na composição de afetos positivos, a auto-estima foi apontada como um conceito psicológico que representava saúde mental, porque incluía uma auto-avaliação em que o próprio indivíduo se reconhece como tendo valor e sendo dotado de características positivas e também negativas. Além do senso pessoal de auto-estima, outros conceitos também foram arrolados como integrantes da dimensão positiva de BES, tais como auto-aceitação, auto-imagem e auto-respeito.

Posteriormente, outros pesquisadores (Diener \& Emmons, 1985; Watson, Clark \& Tellegen, 1988) apresentaram evidências sobre a existência das duas dimensões na estrutura dos afetos apregoadas por Bradburn (1969). Desde então, instalou-se a proposta de se considerar BES como um construto psicológico integrado por experiências emocionais positivas e negativas e a se denominar tais experiências de afetos positivos (positive affects) e afetos negativos (negative affects).

A estrutura bidimensional dos afetos proposta por Bradburn (1969) levou diversos estudiosos a elaborar e validar medidas para aferi-la. Em 1988, Watson e cols. validaram a Lista de Afetos Positivos e Negativos (Positive Affect and Negative Affect Schedule-PANAS), composta de duas escalas com 10 itens cada, que se mostraram, segundo seus autores, consistentes, válidas e eficientes para medir as duas dimensões de afetividade. De acordo com Watson e cols. (1988), AP representa a extensão na qual uma pessoa se sente entusiasta, ativa e alerta. Um nível alto de AP constitui um estado de alta energia, plena concentração e engajamento prazeroso, enquanto baixo AP é caracterizado por tristeza e letargia. Afeto negativo (AN) é uma dimensão geral de engajamento sem prazer, incluindo, em seu nível mais alto, sensações negativas diversas, tais como raiva, desprezo, culpa, medo e nervosismo. O nível mais baixo de AN inclui calma, serenidade e sossego. A escala de AP integrante da PANAS inclui 10 palavras que descrevem sentimentos e emoções positivas (interessado, forte, entusiasmado, orgulhoso, ativo, inspirado, determinado, atento, animado e estimulado), enquanto a escala de AN compõe-se de outras 10 palavras que expressam a dimensão negativa da afetividade (angustiado, descontrolado, culpado, assustado, hostil, irritado, envergonhado, nervoso, inquieto e amedrontado).

Nos anos 1980, os estudos em que foram utilizadas as medidas de estrutura dos afetos aplicaram predominantemente a PANAS. Naquela época, ainda não se apregoava com a ênfase e clareza que se vê hoje a inclusão dos afetos positivos e negativos como dimensões do BES. Dava-se maior ênfase a eles como traços afetivos que se aproximavam muito de determinados traços de personalidade. Enquanto AP era visto como um correlato de dimensões positivas da personalidade como extroversão, AN tornava-se um correspondente de neuroticismo. Os estudos que utilizavam a PANAS procuravam relacionar o conceito genérico de bem-estar a diferentes 
indicadores de doenças mentais ou psicopatologias, tais como depressão, ansiedade e estresse.

No Brasil, já existe uma medida de afetos positivos e negativos. Trata-se da Escala de Ânimo Positivo e Negativo (EAPN), desenvolvida e validada por Siqueira e cols. (1999). A EAPN é uma medida composta por 14 afetos, que se distribuem em duas sub-escalas: a que mede afetos positivos por meio de seis itens (feliz, alegre, animado, bem, satisfeito e contente) e a que avalia afetos negativos por intermédio de oito itens (irritado, desmotivado, angustiado, deprimido, chateado, nervoso, triste e desanimado). Segundo as autoras da medida, os afetos positivos constituem uma sub-escala com índice de precisão de 0,87 , enquanto os afetos negativos compõem uma sub-escala com precisão de 0,88 . As respostas são dadas numa escala de cinco pontos ( $1=$ nada; $2=$ pouco; $3=$ mais ou menos; 4=muito; 5=extremamente) que mede a intensidade com que as pessoas vivenciam os 14 afetos.

Outra medida brasileira da dimensão emocional BES está incluída na Escala de Bem-Estar Subjetivo (EBES) construída e validada por Albuquerque e Tróccoli (2004). A EBES inclui 21 itens de afetos positivos e 26 de afetos negativos, que constituem, respectivamente, os fatores 1 e 2 , ambos com índices de precisão de 0,95 . O terceiro fator avalia, mediante 15 itens, a dimensão cognitiva de BES, satisfação-insatisfação com a vida, cuja precisão é de 0,90 .

A inserção de afetos positivos e negativos na composição emocional de BES se deu, com maior ênfase, nos anos 1970 e 1980, quando diversos autores (Andrews \& Withey, 1976; Campbell \& cols., 1976; Diener, 1984; Emmons, 1986) incluíram os afetos positivos e negativos, ao lado de satisfação com a vida (componente cognitivo), como integrantes de BES.

\section{A dimensão cognitiva de BES: satisfação com a vida}

Satisfação com a vida é o julgamento que o indivíduo faz sobre sua vida (Keyes \& cols., 2002) e que reflete o quanto esse indivíduo se percebe distante ou próximo a suas aspirações (Campbell \& cols., 1976). Trata-se, segundo Neugarten, Havighurst e Tobin (1961), de um estado psicológico que guarda estreita relação com bem-estar mais do que avaliações objetivas da qualidade de vida pessoal. Neugarten e cols., afirmam, ainda, que uma pessoa com alta qualidade de vida poderia relatar insatisfações, enquanto uma pessoa com baixa qualidade de vida poderia até revelar satisfações com a vida.

O conceito é ainda considerado como uma dimensão subjetiva de qualidade de vida, ao lado de felicidade e bem-estar. $\mathrm{Na}$ abordagem objetiva de qualidade de vida, entende-se que saúde, ambiente físico, recursos, moradia e outros indicadores observáveis e quantificáveis contemplam o espectro da qualidade de vida que uma pessoa detém. Por outro lado, a perspectiva subjetiva de qualidade de vida, incluindo-se nela satisfação com a vida, é defendida como uma possibilidade de se levar em conta, em avaliações individuais, diferenças culturais na percepção do padrão de vida. Nesse sentido, aceita-se como relevante que mesmo quando certos grupos compartilham a mesma cultura, observam-se variações entre os indivíduos quanto a suas crenças, valores, objetivos e necessidades. Sem compreender os valores e crenças de uma população e como estes são manifestados individualmente, a avaliação de qualquer tema sobre a vida pessoal seria arbitrária. Parece, portanto, que satisfação com a vida teve suas origens nas concepções de qualidade de vida, tendo sido um conceito apropriado e redefinido por estudiosos das ciências comportamentais para compor um dos elementos que integram a definição de BES.

As tentativas para integrar satisfação com a vida ao conceito de BES são relativamente antigas. A primeira vez que se aproximou o conceito ao de bem-estar foi em uma pesquisa realizada nos Estados Unidos no ano de 1957, coordenada por Gurin e publicada em 1960 (Gurin \& cols., 1960), um survey populacional em que se aferiu níveis de satisfação com a vida, felicidade e moral. Nesse estudo, entretanto, satisfação com a vida era ainda considerada um componente de qualidade de vida, assim como também eram os conceitos de felicidade e moral (Keyes \& cols., 2002).

Nos anos 1980, diversos pesquisadores (George \& Bearon, 1980; Stones \& Kozma, 1980; Stull, 1987) já reconheciam satisfação com a vida como dimensão cognitiva de BES. Reconhecer tal natureza tornou-se importante não só porque era possível distinguir satisfação com a vida do componente emocional de BES, afetos positivos/negativos, como também porque possibilitava compreender como se dava a estruturação dos dois componentes de BES entre amostras com características demográficas distintas. Como conseqüência desse reconhecimento, pôde-se identificar, por exemplo, que pessoas idosas eram mais satisfeitas com suas vidas do que pessoas jovens, mas estas relatavam menos afetos positivos do que aquelas (Andrews \& Robinson, 1991; Campbell, 1981). Ademais, o reconhecimento de satisfação com a vida como componente cognitivo de BES propiciou aos estudiosos em psicologia contar com elaborações teóricas mais consistentes, que lhes permitem investigar bem-estar como um construto formatado dentro dos domínios da psicologia e proceder a investigações usando medidas específicas de cada um dos componentes de BES, bem como avaliar relações entre os seus componentes cognitivo (satisfação com a vida) e emocional (afetos positivos e negativos).

Uma primeira medida de satisfação com a vida foi desenvolvida por Neugarten e colaboradores em 1961. A medida continha duas versões, A e B, construídas para avaliar sentimentos gerais de bem-estar que permitissem identificar envelhecimento bem-sucedido. A versão A contém um checklist de 20 frases, sendo 12 positivas e oito negativas (ex.: Eu tenho tido mais sorte na vida do que a maioria das pessoas) com as quais o respondente concorda ou discorda. A versão B inclui 12 questões abertas sobre as quais é atribuído um escore após análise do conteúdo das respostas (ex.: Qual é a coisa mais importante de sua vida no momento?).

Uma medida de satisfação com a vida, denominada Escala de Satisfação Geral com a Vida - ESGV, foi desenvolvida e validada por pesquisadores no Brasil (Siqueira, Gomide \& Freire, 1996). A ESGV é uma escala unidimensional que contém 31 frases, cobrindo o mesmo número de aspectos, tais como amigos, aparência física e nível de instrução, e permite avaliar o quanto cada indivíduo está satisfeito ou insatisfeito com cada um deles por uma escala de respostas de cinco pontos ( $1=$ muito insatisfeito, $2=$ insatisfeito, $3=$ nem satisfeito nem insatisfeito, $4=$ satisfeito, $5=$ muito satisfeito). A precisão da escala é de 0,70. O largo leque de aspectos integrantes da ESGV permite ao pesquisador ter um panorama geral do nível 
em que indivíduos e grupos se sentem satisfeitos mediante uma avaliação global de sua vida. Portanto, a ESGV não permite avaliar satisfações em domínios específicos da vida.

Na próxima seção, serão apresentadas as origens e as dimensões de outra perspectiva de estudos em psicologia sobre bem-estar, qual seja, aquela em que os pesquisadores se basearam no funcionamento psicológico positivo para erigir o conceito de bem-estar psicológico, também referido por Ryan e Deci (2001) como bem-estar eudemônico.

\section{Bem-Estar Psicológico}

As proposições acerca do conceito de bem-estar psicológico (BEP) apareceram como críticas à fragilidade das formulações que sustentavam BES e aos estudos psicológicos que enfatizaram a infelicidade e o sofrimento e negligenciaram as causas e consequiências do funcionamento positivo.

Os trabalhos de Ryff (1989) e, mais tarde, Ryff e Keyes (1995) são dois marcos na literatura sobre o tema. Segundo esses autores, as formulações teóricas em que se apóiam o campo de estudos de BES são frágeis por diversas razões. Como primeiro argumento, apontam o fato de que o clássico estudo de Bradburn (1969) que sugeriu a existência de duas dimensões na estruturação dos afetos (positivos e negativos) são resultantes do efeito de serendipidade, visto que Bradburn, na época, buscava identificar como certas mudanças sociais de nível macro (mudanças em níveis educacionais, padrões de emprego, urbanização ou tensões políticas) afetavam o padrão de vida dos cidadãos e este o seu senso de bem-estar, dandose atenção mínima para compreensão de bem-estar. De modo similar, satisfação com a vida, postulada como componente cognitivo de BES, surge como tal após deslocamentos do conceito que emergiu no campo sociológico, sem que o mesmo tenha assento teórico consistente em psicologia.

Como segundo argumento para sustentar as proposições de BEP, os autores (Ryff, 1989; Ryff \& Keyes, 1995) afirmam que dentro do campo de teorização psicológica existem diversas teorias que permitem construir concepções sólidas sobre o funcionamento psíquico, enfatizando-se os seus aspectos positivos. Deste corpo teórico, basicamente desenvolvido nos anos 1950 e 1960, seria possível retirar suportes conceituais para conceber o processo aplicado na resolução de desafios que se apresentam durante a vida (Keyes \& cols., 2002) e que constituem o entendimento central de BEP.

Enquanto BES tradicionalmente se sustenta em avaliações de satisfações com a vida e num balanço entre afetos positivos e negativos que revelam felicidade, as concepções teóricas de BEP são fortemente construídas sobre formulações psicológicas acerca do desenvolvimento humano e dimensionadas em capacidades para enfrentar os desafios da vida.

Segundo uma síntese apresentada por Ryff (1989), após análise e revisão da literatura, a estrutura de uma abordagem acerca do funcionamento psicológico positivo apóia-se em diversas teorias clássicas existentes em psicologia que se assentam em uma abordagem clínica, ressaltando-se, entre outras, as que tratam particularmente dos fenômenos da individuação (Jung, 1933), auto-realização (Maslow, 1968), maturidade (Allport, 1961) e completo funcionamento (Rodgers, 1961). Também foram utilizadas, nesse mesmo intento, visões teóricas sobre desenvolvimento humano (Erickson, 1959; Neugarten,
1973), incluindo-se nesse domínio o uso das formulações sobre estágios de desenvolvimento, bem como as descrições de mudanças na personalidade nas fases adulta e de velhice. Ao lado de todas essas vertentes, também foram utilizadas as proposições relativas à saúde mental (Jahoda, 1958), aplicadas para justificar o conceito de bem-estar como ausência de doença e fortalecer o significado de saúde psicológica. Tomando como referenciais todas essas concepções teóricas e, especialmente, as que permitiam delas abstrair visões distintas do funcionamento psicológico positivo, Ryff (1989) elaborou uma proposta integradora ao formular um modelo de seis componentes de BEP, reorganizado e reformulado posteriormente por Ryff e Keyes (1995), cujas definições são apresentadas a seguir:

Auto-aceitação: Definida como o aspecto central da saúde mental, trata-se de uma característica que revela elevado nível de autoconhecimento, ótimo funcionamento e maturidade. Atitudes positivas sobre si mesmo emergem como uma das principais características do funcionamento psicológico positivo.

Relacionamento positivo com outras pessoas: Descrito como fortes sentimentos de empatia e afeição por todos os seres humanos, capacidade de amar fortemente, manter amizade e identificação com o outro.

Autonomia: São seus indicadores o locus interno de avaliação e o uso de padrões internos de auto-avaliação, resistência à aculturação e independência acerca de aprovações externas.

Domínio do ambiente: Capacidade do indivíduo para escolher ou criar ambientes adequados às suas características psíquicas, de participação acentuada em seu meio e manipulação e controle de ambientes complexos.

Propósito de vida: Manutenção de objetivos, intenções e de senso de direção perante a vida, mantendo o sentimento de que a vida tem um significado.

Crescimento pessoal: Necessidade de constante crescimento e aprimoramento pessoais, abertura a novas experiências, vencendo desafios que se apresentam em diferentes fases da vida.

Por meio de um estudo com amostra nacional de 3.032 americanos com idade entre 25 e 74 anos, Keyes e cols. (2002) procuraram apresentar evidências empíricas sobre as relações entre BES e BEP. Análises fatoriais confirmaram que os dois conceitos, embora mantivessem correlações entre si, poderiam ser considerados distintos e serem mantidas suas identidades conforme consta na literatura. Os resultados do estudo também revelaram que um estado ótimo de bem-estar, definido pelas autoras como alto BES e alto BEP, aumentava com a idade, com o nível educacional, com fortes traços disposicionais, tais como extroversão e conscienciosidade, mas decrescia com o neuroticismo, considerado este último um componente negativo da personalidade. Ao observar entre os participantes adultos de sua amostra quais eram as características de pessoas que apresentavam BES superior a BEP ou o inverso, verificou-se que entre eles estavam os mais jovens, que galgaram níveis educacionais mais elevados e que mostravam, como traço de personalidade, maior abertura a experiências.

\section{Bem-Estar no Trabalho}

Ainda não existem na literatura concepções claras sobre o conceito de bem-estar no trabalho. Quando tratam do assunto, os pesquisadores escolhem conceitos diversos para 
representá-lo, quer seja um fator positivo como satisfação com o trabalho (Amaral \& Siqueira, 2004) quer seja conceitos negativos como burnout (Maslach, Schaufeli \& Leiter, 2001) ou estresse (Byrne, 1994). Ademais, bem-estar e saúde são abordados de forma interdependente, especialmente quando os pesquisadores apontam fatores que possam comprometer ambos, tais como perigos do ambiente de trabalho, fatores de personalidade e estresse ocupacional (Danna \& Griffin, 1999) ou, ainda, segurança no trabalho, horas trabalhadas, controle do trabalho e estilo gerencial (Sparks, Fargher \& Cooper, 2001).

Para os propósitos deste artigo, bem-estar no trabalho é concebido como um conceito integrado por três componentes: satisfação no trabalho, envolvimento com o trabalho e comprometimento organizacional afetivo. Esses três conceitos, já consolidados no campo da Psicologia Organizacional e do Trabalho, representam vínculos positivos com o trabalho (satisfação e envolvimento) e com a organização (comprometimento afetivo) conforme relatam Siqueira e Gomide Jr. (2004).

Foi tomada como referência teórica para as formulações acerca do conceito de bem-estar no trabalho as proposições de Diener e cols. (2003) sobre a estruturação do conceito de bem-estar subjetivo, apresentada pelos autores como um modelo hierárquico de felicidade. Nesse modelo, os autores defendem que bem-estar subjetivo reflete uma avaliação geral da vida e que pesquisadores interessados em investigá-lo deveriam avaliar diversos componentes de níveis inferiores na hierarquia. No topo da hierarquia, quatro grandes componentes representam bem-estar subjetivo: afetos positivos, afetos negativos, satisfação geral com a vida e satisfação com domínios específicos. Essa estrutura de quatro componentes inclui, na realidade, duas grandes dimensões psicológicas: emoções e cognições. Representando as emoções estão afetos positivos e negativos e representando as cognições estão as avaliações geral e específicas sobre a vida.

Com inspiração nesse modelo, sugere-se que bem-estar no trabalho possa ser entendido como um construto psicológico multidimensional, integrado por vínculos afetivos positivos com o trabalho (satisfação e envolvimento) e com a organização (comprometimento organizacional afetivo). A estrutura proposta para o conceito de bem-estar no trabalho aglutina três conceitos com conotações positivas, na medida em que abarca ligações prazerosas no contexto de trabalho, como demonstrado a seguir pelas definições contidas na literatura:

Satisfação no trabalho: "[...] um estado emocional positivo ou de prazer, resultante de um trabalho ou de experiências de trabalho." (Locke, 1976, p. 1.300).

Envolvimento com o trabalho: "[...] grau em que o desempenho de uma pessoa no trabalho afeta sua auto-estima" (Lodahl \& Kejner, 1965, p. 25).

Comprometimento organizacional afetivo: "[...] um estado no qual um indivíduo se identifica com uma organização particular e com seus objetivos, desejando manter-se afiliado a ela com vista a realizar tais objetivos" (Mowday, Steers \& Porter, 1979, p. 225).

As três definições acima representam as concepções seminais dos três conceitos. Entretanto, para integrar o conceito de bem-estar no trabalho, considera-se necessário avançar sobre essas concepções.

Mais recentemente, satisfação no trabalho, embora persistam controvérsias quanto à sua natureza cognitiva ou afetiva, tem sido apontada como um vínculo afetivo positivo com o trabalho, e têm sido definidas como aspectos específicos deste vínculo as satisfações que se obtêm nos relacionamentos com as chefias e com os colegas de trabalho, as satisfações advindas do salário pago pela empresa, das oportunidades de promoção ofertadas pela política de gestão da empresa e, finalmente, das satisfações com as tarefas realizadas. Portanto, o conceito de satisfação evoluiu para uma concepção multidimensional, que envolve avaliações prazerosas sobre cinco domínios específicos no ambiente de trabalho (Siqueira \& Gomide Jr, 2004).

Envolvimento com o trabalho, após mais de quatro décadas de sua concepção original proposta por Lodhal e Kejner (1965), permite compreendê-lo mais contemporaneamente como um estado de fluxo (Csikszentmihalyi, 1997/1999). Para compreensão dessa abordagem, faz-se necessário entender o que significa estado de fluxo. Segundo Csikszentmihalyi (1997/1999), o estado de fluxo ocorre em momentos em que o que sentimos, desejamos e pensamos se harmonizam. Esses momentos

[...] costumam ocorrer quando alguém encara metas que exigem respostas apropriadas. É fácil entrar em fluxo em jogos de xadrez, tênis ou pôquer, porque eles possuem metas e regras para a ação que tornam possível ao jogador agir sem questionar o que deve ser feito e como fazê-lo (p. 36).

Ainda segundo o autor, atividades ou experiências de fluxo ocorrem quando há concentração em metas, há feedback imediato e quando altos desafios são respondidos por altas habilidades individuais. Nessas condições, a energia de um indivíduo estaria concentrada na experiência: desaparecem pensamentos e sentimentos contraditórios, esvai-se a noção de tempo e as horas parecem passar como minutos. Para avaliar se alguém é capaz de experimentar um estado de fluxo, o autor propõe que se responda à seguinte questão: "Você se envolve em algo tão profundamente que nada mais parece importar, a ponto de perder a noção do tempo?" (Csikszentmihalyi, 1997/1999, p. 40).

Na visão de Csikszentmihalyi (1997/1999), o trabalho também produz fluxo. Isso ocorre quando as atividades de trabalho incluem desafios que exigem habilidades especiais e as metas estabelecidas e o feedback são claros e imediatos. Nessas condições, o trabalho se assemelha a atividades que produzem fluxo, desencadeando no indivíduo maior envolvimento e transformando a atividade em uma experiência positiva. Assim, poderiam florescer sensações muitos semelhantes às que se experimentam quando alguém pratica seu esporte favorito ou desempenha uma atividade artística. Nesse sentido, o envolvimento com o trabalho seria um conceito muito próximo à noção de fluxo.

O terceiro componente apontado neste artigo como integrante do conceito de bem-estar no trabalho é o comprometimento organizacional afetivo. Ele representa a concepção de ligação positiva do empregado com um empregador, de elevada identificação com os objetivos da organização 
(Borges-Andrade, 1994; Mowday \& cols., 1979) e de reconhecimento sobre o quanto estar ligado àquela organização pode repercutir positivamente na vida do indivíduo A ligação afetiva com uma organização pode incluir experiências emocionais positivas, que se traduzem em sentimentos positivos como entusiasmo, orgulho, contentamento, confiança, apego e dedicação (Siqueira, 1995). Com essa concepção, o comprometimento afetivo traz para o conceito de bem-estar no trabalho uma visão de que as relações estabelecidas pelo indivíduo com a organização que o emprega estão assentadas em uma interação que lhe propicia vivências positivas e prazerosas. Caso essa situação não se confirme, entende-se que poderiam ser experimentadas sensações negativas ou de desprazer por trabalhar em uma organização. Nesse caso, seria observada ausência do compromisso afetivo e possível desencadeamento de experiências negativas no dia-a-dia do trabalhador.

Para que se possa observar entre trabalhadores um nível elevado de bem-estar no trabalho, seria necessário que eles relatassem estar satisfeitos com o trabalho, reconhecessem envolvimento com as tarefas que realizam e, finalmente, revelassem que mantêm compromisso afetivo com a organização empregadora.

\section{Considerações Finais}

As perspectivas teóricas sobre bem-estar apresentadas comungam uma forte reação à ênfase dada em psicologia, desde seus primórdios, à infelicidade e ao sofrimento em detrimento aos antecedentes e consequiências do funcionamento psicológico positivo. O desafio que aproxima pesquisadores de bem-estar reside na busca de introduzir no campo de teorização e práticas psicológicas uma concepção diferenciada daquela que tem atraído e monopolizado a atenção de estudiosos e profissionais em psicologia: apresentar novas visões sobre o funcionamento psíquico positivo. Esse esforço, mais articulado a partir dos anos 1980 pela proposição de Ryff (1985) ao conceber o conceito de BEP, foi recentemente fortalecido pelo artigo de Seligman e Csikszentmihalyi (2000), ao apresentarem os pressupostos de uma psicologia positiva. Os dois autores entendem que uma ciência preocupada com a experiência subjetiva positiva, com traços individuais positivos e com instituições positivas possa contribuir mais para melhorar a qualidade de vida das pessoas e prevenir patologias. Acreditam e apregoam que por esse esforço seria possível levar cientistas e profissionais a compreender e propor alternativas que levariam indivíduos, comunidades e sociedades a florescer.

Para viabilizar a proposta imbricada nos pressupostos da psicologia positiva, seria necessário que pesquisadores tentassem compreender os processos que fortalecem os indivíduos diante de adversidades, doenças e infortúnios; que tentassem identificar nas instituições sociais quais fatores contribuem para desenvolver e fortalecer características pessoais positivas e estratégias psicológicas que tornam as pessoas fortes, mesmo diante de infortúnios; traduzir em procedimentos preventivos institucionais as práticas sociais que contribuem para o fortalecimento individual; alertar a comunidade, os grupos sociais, as famílias, os dirigentes institucionais e empresariais sobre o vasto leque de potenciais positivos que indivíduos, grupos, famílias e instituições podem comparti- lhar e desfrutar na construção de uma existência mais feliz, saudável e plena de realizações.

Os estudos e debates acerca da identidade, dos componentes particulares e da interdependência entre os já tradicionais conceitos de bem-estar subjetivo e bem-estar psicológico, acrescidas das proposições apresentadas neste artigo sobre a concepção e os componentes de bem-estar no trabalho, são contribuições que consolidam os princípios da psicologia positiva. Entretanto, deve-se ressaltar que uma vasta lista de outros conceitos positivos permeiam a literatura psicossocial. Entre eles podem ser apontados os que giram ao redor de um eixo de características pessoais positivas como otimismo, esperança, auto-estima, inteligência emocional, valores pessoais como auto-transcedência e abertura. Dos grupos, das instituições e da comunidade podem ser elencados fatores que, entre outros, acolhem, protegem e promovem o indivíduo, tais como responsabilidade, suporte e justiça sociais. É nesse contexto que deverão despontar as virtudes cívicas dos cidadãos, que os defensores da psicologia positiva ressaltam como atributos sociais a serem investigados. Assim, os debates acadêmicos sobre o complexo conceito de bem-estar contam hoje com uma base teórica já desenvolvida, mas o avanço dos estudos deveria entrelaçar, sempre que possível, outros conceitos psicossociais positivos para que se possa tecer uma rede integrada de conhecimentos com outras disciplinas sociais, capaz de responder mais satisfatoriamente ao desafio de se construir uma sociedade mais justa e solidária em que os indivíduos possam desfrutar de níveis mais elevados de bem-estar.

\section{Referências}

Albuquerque, A. S. \& Tróccoli, B. T. (2004). Desenvolvimento de uma escala de bem-estar subjetivo. Psicologia: Teoria e Pesquisa, 20(2), 153-164.

Allport, G. W. (1961). Pattern and growth in personality. New York: Holt, Rinehart \& Winston.

Amaral, D..J. \& Siqueira, M..M..M. (2004). Relações entre percepção da estrutura organizacional e bem-estar de profissionais de uma empresa em processo de privatização. Em J. Ribeiro \& I. Leal (Orgs.), Actas do $5^{\circ}$ Congresso Nacional de Psicologia da Saúde (pp. 671-677). Lisboa: Fundação Calouste Gulbenkian.

Andrews, F. M. (1991). Stability and change in levels and structure of subjective well being: USA 1972 and 1988. Social Indicators Research, 25, 1-30.

Andrews, F. M. \& Robinson, J. P. (1991). Measures of subjective well being. Em J. P. Robinson, P. R. Shaver \& L. S. Wrightsman (Orgs.), Measures of Personality and Social Psychological Attitudes (pp. 61-114). San Diego: Academic Press.

Andrews, F. M. \& Withey, S. B. (1976). Social indicators of well-being. New York: Plenun Press.

Borges-Andrade, J. E. (1994). Conceituação e mensuração de comprometimento organizacional. Temas em Psicologia, 1, 37-47.

Bradburn, N. M. (1969). The structure of psychological well being. Chicago: Aldine Publishing.

Bradburn, N. M. \& Caplovitz, D. (1965). Reports on happiness: A pilot study of behavior related to mental health. Chicago: Aldine Publishing.

Byrne, B. M. (1994). Burnout: Testing for the validity, replication, and invariance of causal structure across elementary, intermediate, and 
secondary teachers. American Educational Research Journal, 31, 645-673.

Campbell, A. (1981). The sense of well being in America. New York: McGraw-Hill.

Campbell, A., Converge, P. E. \& Rodgers, W. L. (1976). The quality of American life. New York: Russell Stage Foundation.

Cantril, H. (1967). The pattern of human concerns. New Burnswick: Rutgers University Press.

Capitanini, M. E. S. (2000). Sentimento de solidão, bem-estar subjetivo e relações sociais em idosas vivendo sós. Dissertação de Mestrado, Universidade Estadual de Campinas, São Paulo.

Csikszentmihalyi, M. (1999). A descoberta do fluxo: a psicologia do envolvimento com a vida cotidiana. (P. Ribeiro, Trad.), Rio de Janeiro: Rocco. (Trabalho original publicado em 1997)

Danna, K. \& Griffin, R. W. (1999). Healthy and well being in the workplace: A review and synthesis of the literature. Journal of Management, 25(3), 357-384.

Diener, E. (1984). Subjective well being. Psychological Bulletin, 95, 542-575.

Diener, E. \& Diener, C. (1996). Most people are happy. Psychological Science, 7, 181-185.

Diener, E. \& Emmons, R. A. (1985). The independence of positive and negative affect. Journal of Personality and Social Psychology, 47, 1105-1117.

Diener, E. \& Lucas, R. F. (2000). Subjective emotional well being. Em M. Lewis \& J. M. Haviland (Orgs.), Handbook of Emotions (pp. 325-337). New York: Guilford.

Diener, E., Scollon, C. N. \& Lucas, R. E. (2003). The involving concept of subjective well being: The multifaceted nature of happiness. Advances in Cell Aging and Gerontology, 15, 187-219.

Diener, E., Suh, E. M., Lucas, R. E. \& Smith, H. L. (1999). Subjective well being: Three decades of progress. Psychological Bulletin, 125(2), 276-302.

Diener, E., Suh, E. \& Oishi, S. (1997). Recent findings on subjective well being. Indian Journal of Clinical Psychology, 24(1), 25-41.

Emmons, R. A. (1986). Personal strivings: An approach to personality and subjective well being. Journal of Personality and Social Psychology, 51, 1058-1068.

Erickson, E. (1959). Identify and the life cycle. Psychological Issues, 1, 18-164.

Freire, S. A. (2001). Bem-estar subjetivo e metas de vida: um estudo transversal com homens e mulheres pertencentes a três faixas de idade. Tese de Doutorado, Universidade Estadual de Campinas, São Paulo.

George, L. K. \& Bearon, L. B. (1980). Quality of life in older persons: Meaning and measurement. New York: Human Science Press.

Gurin, G., Veroff, J. \& Feld, S. (1960). American views their mental health. New York: Basic Books.

Jahoda, M. (1958). Current concepts of positive mental health. New York: Basic Books.

Jung, C.G. (1933). Modern man in search of a soul. New York: Harcourt, Brace \& World.

Keyes, C. L. M., Shmotkin, D. \& Ryff, C. D. (2002). Optimizing well being: The empirical encounter of two traditions. Journal of Personality and Social Psychology, 82(6), 1007-1022.

Land, K. C. (1975). Social indicators models: An overview. In K. C. Land \& S. Spilerman (Orgs.), Social indicator models (pp. 5-36). New York: Russell Sage Foundation.
Locke, E. A. (1976). The nature and causes of job satisfaction. Em M. P. Dunnette (Org.), Handbook of Industrial and Organizational Psychology (pp. 1294-1349). Chicago: Rand-McNally.

Lodahl, T. M. \& Kejner, M. (1965). The definition and measurement of job involvement. Journal of Applied Psychology, 49, 23-33.

Maslach, C., Schaufeli, W. B. \& Leiter, M. P. (2001). Job burnout. Annual Review of Psychology, 52, 397-422.

Maslow, A. (1968). Toward a psychology of being (2a ed.). New York: Van Nostrand.

Mowday, R. T., Steers, R. M. \& Porter, L. W. (1979). The measurement of organizational commitment. Journal of Vocational Behavior, 14, 224-247.

Neugarten, B. L. (1973). Personality change in late life: A developmental perspective. Em C. Eisdorfer \& M. P. Lawton (Orgs.), The psychology of adult development and aging (pp. 311-335). Washington: American Psychological Association.

Neugarten B. L., Havighurst, R. J. \& Tobin, S. S. (1961). The measurement of life satisfaction. Journal of Gerontology, 16, 134-146.

Prebianchi, H. B. (2003) Medidas de qualidade de vida para crianças: aspectos conceituais e metodológicos. Psicologia: Teoria e Prática, 5(1), 57-69.

Ostrom, T. M. (1969). The relationship between affective, behavioral and cognitive components of attitude. Journal of Experimental Psychology, 5, 12-30.

Rodgers, C. R. (1961). On becoming a person. Boston: Houghton Mifflin.

Ryan, R. M. \& Deci, E. L. (2001). On happiness and human potentials: A review of research on hedonic and eudaimonic well being. Annual Review of Psychology, 52, 141-166.

Ryff, C. D. (1989). Happiness is everything, or is it? Explorations on the meaning of psychological well being. Journal of Personality and Social Psychology, 57, 1069-1081.

Ryff, C. D. \& Keyes, C. L. M. (1995). The structure of psychological well being revisited. Journal of Personality and Social Psychology, 69, 719-727.

Seligman, M. E. P. \& Csikszentmihalyi, M. (2000). Positive psychology: An introduction. American Psychologist, 55, 5-14.

Siqueira, M. M. M. (1995). Antecedentes de comportamentos de cidadania organizacional: análise de um modelo pós-cognitivo. Tese de Doutorado, Universidade de Brasília, Brasília.

Siqueira, M. M. M. \& Gomide Jr., S. (2004). Vínculos do indivíduo com o trabalho e com a organização. Em J. C. Zanelli, J. E. BorgesAndrade \& A. V. B. Bastos (Orgs), Psicologia, organizações e trabalho no Brasil (pp. 300-328). Porto Alegre: Artmed.

Siqueira, M. M. M., Gomide Jr, S. \& Freire, S. A. (1996). Construção e validação de uma Escala de Satisfação Geral com a Vida (ESGV). Manuscrito não publicado, Universidade Federal de Uberlândia, Uberlândia.

Siqueira, M. M. M., Martins M. C. F. \& Moura, O. I. (1999). Construção e validação fatorial da EAPN: Escala de Ânimo Positivo e Negativo. Revista da Sociedade de Psicologia do Triângulo Mineiro, 2(3), 34-40.

Sparks, K., Fargher, B. \& Cooper, C. L. (2001). Well being and occupational health in the $21^{\text {st }}$ century workplace. Journal of Occupational and Organizational Psychology, 74, 489-509.

Stones, M. L. \& Kosma, A. (1980). Issues relating to the usage of conceptualizations of mental constructs employed by gerontologists. International Journal of Aging and Human Development, 11, 269-281. 
Stull, D. E. (1987). Conceptualization and measurement of well being: Implications for policy evaluation. Em E. F. Borgatta \& R. J. V. Montgomery (Orgs.), Critical Issues in Aging Policy (pp. 40-58). Beverly Hills: Sage Publications.

Thomas, D. \& Diener, E. (1990). Memory accuracy in the recall of emotions. Journal of Personality and Social Psychology, 59, 291-297.

Watson, D., Clark, E. \& Tellegen, A. (1988). Development and validation of brief measures of positive and negative affect: The
PANAS scales. Journal of Personality and Social Psychology, 54, 1063-1070.

Wilson, W. (1967). Correlates of avowed happiness. Psychological Bulletin, 67, 294-306.

Recebido em 15.09.2005

Primeira decisão editorial em 27.09.2006

Versão final em 30.10.2006

Aceito em 11.12.2007 